\title{
Role of prediabetes in stroke
}

REVIEW

This article was published in the following Dove Press journal:

Neuropsychiatric Disease and Treatment

2 February 2017

Number of times this article has been viewed

\author{
Milija D Mijajlovićl,* \\ Vuk M Aleksić ${ }^{2, *}$ \\ Nadežda M Šternićl \\ Mihailo M Mirković ${ }^{3}$ \\ Natan M Bornstein ${ }^{4,5}$ \\ 'Neurology Clinic, Clinical Center \\ of Serbia, School of Medicine \\ University of Belgrade, ${ }^{2}$ Department \\ of Neurosurgery, Clinical Hospital \\ Center Zemun, Belgrade, ${ }^{3}$ Department \\ of Neurology, General Hospital \\ Valjevo, Valjevo, Serbia; ${ }^{4}$ Department \\ of Neurology, Tel-Aviv Sourasky \\ Medical Center, Tel-Aviv University, \\ Tel-Aviv, ${ }^{5}$ Shaare Zedek Medical \\ Center, Jerusalem, Israel \\ *These authors contributed equally \\ to this work
}

Correspondence: Milija D Mijajlović Neurology Clinic, Clinical Center of Serbia, School of Medicine University of Belgrade, Dr Subotica 6, I 1000 Belgrade, Serbia

Tel +38I II 3064265

Fax +38I II 2684577

Email milijamijajlovic@yahoo.com
Abstract: Stroke is one of the leading causes of death and probably the greatest cause of adult disability worldwide. Diabetes mellitus (DM) is a state of accelerated aging of blood vessels. Patients with diabetes have increased risk of stroke. Hyperglycemia represents a risk factor for poor outcome following stroke, and probably is just a marker of poor outcome rather than a cause. Lowering of blood glucose levels has not been shown to improve prognosis. Also, prevention of stroke risk among patients with DM is not improved with therapy for reduction of glucose levels. On the other hand, prediabetes, a metabolic state between normal glucose metabolism and diabetes, is a risk factor for the development of DM type 2 and subsequently for stroke. Several methods are known to identify prediabetes patients, including fasting plasma glucose levels, 2-hour post load glucose levels, and glycosylated hemoglobin levels. In this text, we tried to summarize known data about diagnosis, epidemiology, risk factors, pathophysiology, and prevention of prediabetes in relation to DM and stroke.

Keywords: diabetes mellitus, insulin, metabolic syndrome, prediabetes, risk factors, stroke

\section{Introduction}

A comprehensive review of available evidence and data sources on diagnosis, epidemiology, risk factors, pathophysiology, and prevention of prediabetes in relation to diabetes mellitus (DM) and stroke was conducted through standard literature online databases research for relevant articles published in English language. Additionally, reference lists of included studies were manually checked for additional references.

In 2011, stroke was the second most frequent cause of death worldwide. Approximately 17 million people had a stroke in 2010. Besides being one of the top major killers, stroke is also a leading cause of disability. ${ }^{1} \mathrm{DM}$ and hyperglycemia are risk factors for ischemic stroke. DM doubles the risk of ischemic stroke and worsens survival of acute stroke patients. On the other hand, prediabetes, a metabolic state between normal glucose metabolism and DM type 2, is a risk factor for the development of DM type 2. More than 2/3 of prediabetic patients develop DM type 2. ${ }^{2}$ The annual risk of developing DM type 2 in people with normal glucose level is $0.7 \%$, whereas patients with prediabetes have a yearly risk of up to $10 \%{ }^{3}$

Prediabetes state includes impaired fasting glucose (IFG) and/or impaired glucose tolerance (IGT) and/or impaired glycosylated hemoglobin (HbA1c). Almost 7\% of adults have either IFG or IGT, and the prevalence of these disorders is greater than that of type 2 diabetes.

The diagnostic criteria for prediabetes have changed during the last couple of years, and in 2010, the American Diabetes Association (ADA) included HbA1c as diagnostic criterion for prediabetes state, ranging from $5.7 \%$ to $6.4 \% .^{4}$ In the same year, the estimated global prevalence of IGT was 7.9\%. In Europe, this number was even higher, $8.9 \% .{ }^{5}$ Because of 2 different criteria for IFG, one proposed by the ADA 
and the other by the World Health Organization (WHO), data about prevalence significantly differ. However, estimated IFG prevalence is about 5\%. ${ }^{6}$ Hyperglycemia is a well-known risk factor for cardiovascular diseases. Prediabetes patients have an increased risk of cardiovascular and cerebrovascular diseases, such as transient ischemic attack (TIA), stroke, and recurrent stroke. Also, these patients are candidates for the development of DM type $2 .^{7,8}$ About $70 \%$ of these patients may develop DM type 2, and more importantly, modification of lifestyle may produce a $40 \%-70 \%$ reduction in relative risk of DM type 2., ${ }^{2,9}$ In addition, prediabetes is associated with early forms of small fiber neuropathy, diabetic retinopathy, nephropathy, and chronic kidney disease. ${ }^{9}$ Also, about $50 \%$ of the nondiabetic patients with a recent TIA or stroke have prediabetes, which is obviously more than in the general population. ${ }^{6}$

\section{Prediabetes diagnosis}

Several methods are known to identify prediabetes patients, including fasting plasma glucose levels, 2-hour post load glucose levels, and HbA1c levels. The cutoff values for diagnosis of prediabetes and DM are shown in Figure 1.

\section{Impaired fasting plasma glucose}

IFG is a common disorder of glucose metabolism, and is considered a state of prediabetes associated with increased risk of DM. ${ }^{10}$ It refers to a state in which blood glucose level after fasting is elevated, although the abnormality has not reached the threshold for a diagnosis of DM. Fasting plasma glucose levels are commonly used to confirm IFG. After fasting during night for minimum 8 hours, plasma glucose levels are measured. However, IFG definition and diagnosis criteria are not clear. There are different cutoff levels for diagnosis of IFG. The WHO uses the higher cutoff point than the ADA.

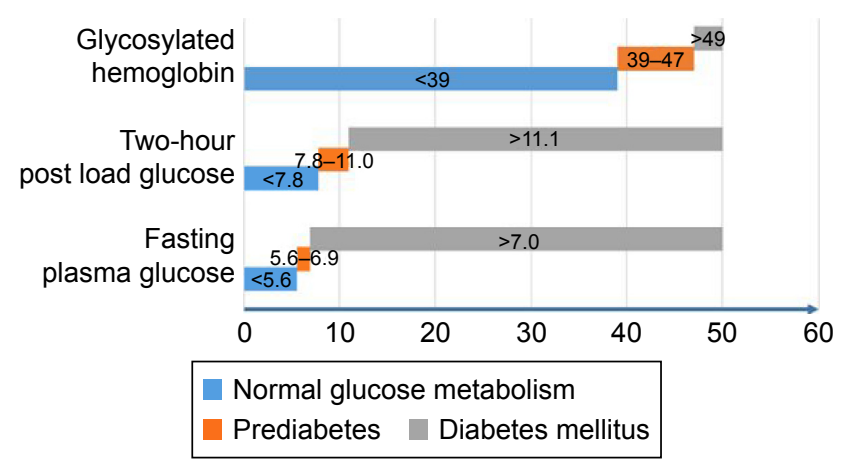

Figure I Cutoff values for prediabetes and DM.

Note: Values are in $\mathrm{mmol} / \mathrm{L}$ for 2-hour post load glucose and fasting plasma glucose and in $\mathrm{mmol} / \mathrm{mol}$ for glycosylated hemoglobin.

Abbreviation: DM, diabetes mellitus.
According to the WHO, the lower cutoff point for IFG is $6.1 \mathrm{mmol} / \mathrm{L}$, while the ADA reduced this level to $5.6 \mathrm{mmol} / \mathrm{L}$ in 2003. ${ }^{2,4}$ This reduction was made because patients with a fasting blood glucose level of between 5.6 and $6.1 \mathrm{mmol} / \mathrm{L}$ exhibit a higher prevalence of DM compared to people with a fasting blood glucose level lower than $5.6 \mathrm{mmol} / \mathrm{L} .{ }^{11}$ This leads to confusion because both of the criteria are used for diagnosis in different stroke trials.

\section{Impaired glucose tolerance}

IGT is a prediabetic state of hyperglycemia that is associated with insulin resistance and increased risk of cardiovascular incident. IGT may precede DM type 2 by many years. IGT is also a risk factor for mortality. The risk of progression to diabetes and development of cardiovascular disease is greater than for IFG. ${ }^{12}$ IGT can be detected with oral glucose tolerance test. After fasting over night, a solution of $75 \mathrm{~g}$ glucose and $150 \mathrm{~mL}$ water is ingested and 2 hours after, glucose levels are measured. ${ }^{13}$ According to the criteria of the WHO and the ADA, IGT is diagnosed when 2-hour glucose level is between 140 to $199 \mathrm{mg}$ per $\mathrm{dL}(7.8-11.0 \mathrm{mmol} / \mathrm{L})$. Regarding IGT, the WHO and the ADA definitions are the same, unlike for IFG.

\section{Impaired HbAlc}

Levels of HbA1c are most frequently used as a diagnostic marker of chronic hyperglycemia in the evaluation of known DM patients. The glucose levels of the previous 3 months are reflected with this diagnostic tool. However, recently, the ADA, the International Diabetes Federation, and the European Association for the Study of Diabetes published a paper in which the use of HbAlc levels was recommended for the diagnosis of prediabetes. The advantage of HbA1c levels over fasting plasma glucose and 2-hour post load glucose in identifying prediabetes in a recent stroke patients is that it remains unaffected by the acute-phase glucose reaction. ${ }^{14}$

The ADA recommends an $\mathrm{HbA} 1 \mathrm{c}$ level over $6.5 \%$ as one of the criteria for the diagnosis of DM. ${ }^{1}$ Some prospective studies used HbA1c to predict progression to DM, showing strong relationship between values of $\mathrm{HbA} 1 \mathrm{c}$ and subsequent DM. The majority of authors agree that it is reasonable to consider an $\mathrm{HbA} 1 \mathrm{c}$ level range between $5.7 \%$ and $6.4 \%$ for identifying patients with prediabetes. ${ }^{15}$ Such patients and those with IGT and IFG must be informed of their increased risk for developing DM and cerebrovascular diseases and taught about effective treatments to lower their risks. Patients with HbA1c levels higher than 6\% are considered to be at very high risk for developing DM. 
The compliance among these 3 tests (fasting plasma glucose, 2-hour post load glucose, and HbAlc levels) is not $100 \%$. Also, several studies showed that the use of fasting plasma glucose levels alone is not enough to detect prediabetes. ${ }^{6}$ Therefore, it is recommended, if possible, to use multiple diagnostic approach.

\section{Prediabetes and stroke epidemiology}

The WHO considers DM as one of the most common public health problems, which will strike a total population of 220 million worldwide in the next 5 years. ${ }^{16}$ On the other hand, prediabetes is called "America's epidemic healthcare problem", and current estimates indicate that about $1 / 3$ of adults in the US have prediabetes, or approximately 80 million people. Also, the problem is that the majority of people with prediabetes are unaware of their risk of DM development. However, one must not forget that prediabetes epidemiology highly depends on the used diagnostic tool/method. Using IGT and IFG level-based criteria, about $10 \%$ of the adult people are in prediabetes state, whereas $\mathrm{HbA} 1 \mathrm{c}$-based criteria identify a significantly lower proportion of the population. ${ }^{5,17}$

According to some authors, there are 3 possibilities for people with prediabetes. About $1 / 3$ of patients will develop DM type 2, the other third will remain unchanged, and the remaining $1 / 3$ of cases may become normoglycemic. ${ }^{18}$ The prevalence of prediabetes in previously normoglycemic nondiabetic patients who suffered a recent TIA or an ischemic stroke is about $37 \%$, ranging from $31 \%$ to $53 \%$ within the first 90 days after the vascular event (acute phase) and about $32 \%$ in the post-acute phase (ranging from $23 \%$ to $46 \%$ ), which is obviously higher than in the overall population. ${ }^{6,19-21}$

Several studies assessed the prevalence of prediabetes and DM type 2 in patients who had stroke (or TIA/intracerebral hemorrhage). In Tables 1 and 2, there is an overview of studies assessing the prevalence of prediabetes and DM type 2 in stroke patients, measuring glucose levels in the acute phase (during the first 90 days after the vascular event) and in the post-acute/ chronic stroke phase (3 or more months after the vascular event), respectively. ${ }^{6}$ In majority of studies, prevalence was assessed by oral glucose tolerance test (OGTT) and fasting plasma glucose. Most of the studies were performed in patients with ischemic stroke as the main vascular event. Patients were recruited from different parts of the world, mostly from Europe, but also from Japan, People's Republic of China, South Africa, and the US. The prevalence of DM type 2 and prediabetes is influenced by ethnicity and this should be taken into account when considering these data. ${ }^{6,22}$ The majority of acute stroke patients have disorders of glucose metabolism, and in most cases this fact has been unrecognized. DM and prediabetes worsen the acute stroke outcome, and therefore in the postacute/chronic phase, an OGTT should be performed in all stroke patients with no prior history of DM or prediabetes.

\section{Risk factors for prediabetes}

Risk factors for prediabetes are similar to DM type 2 risk factors. Those risk factors can be divided into non-modifiable and modifiable risk factors. The most important risk factors are lack of physical activity and obesity (particularly abdominal). Risk factors are summarized in Table 3.

\section{Genetic factors}

There is an obvious difference of prediabetes and DM type 2 prevalence among different ethnic groups even though they share the same environment, which indicates that genetic factor may have a significant role in the development of prediabetes and DM. ${ }^{18,23}$ Also, DM type 2 is more common in African Americans than in European people. ${ }^{24}$ To date,

Table I Overview of data assessing the prevalence of prediabetes and DM type 2 in stroke/TIA/ICH patients during the acute stroke phase ( $<3$ months after vascular event)

\begin{tabular}{|c|c|c|c|c|c|c|}
\hline Population & $\begin{array}{l}\text { Vascular } \\
\text { event }\end{array}$ & $\begin{array}{l}\text { Glucose } \\
\text { measurement }\end{array}$ & $\begin{array}{l}\text { Number } \\
\text { of patients }\end{array}$ & $\begin{array}{l}\text { Normoglycemic, } \\
\text { n (\%) }\end{array}$ & $\begin{array}{l}\text { Prediabetes, } \\
\text { n (\%) }\end{array}$ & $\begin{array}{l}\text { DM type 2, } \\
\text { n (\%) }\end{array}$ \\
\hline Europe & IS & OGTT & 96 & $15(16)$ & $37(39)$ & $44(46)$ \\
\hline Europe & IS, TIA, ICH & FPG, OGTT & 190 & $94(49)$ & $57(30)$ & $39(2 I)$ \\
\hline Japan & IS & FPG, OGTT & 113 & $42(37)$ & $43(38)$ & $28(25)$ \\
\hline South Africa & IS & FPG, OGTT & 107 & $42(39)$ & $39(36)$ & $26(24)$ \\
\hline China & IS & FPG, OGTT & I,793 & 706 (39) & $556(31)$ & $531(30)$ \\
\hline US & IS & $\mathrm{HbAlc}$ & 166 & $53(32)$ & $88(53)$ & $25(15)$ \\
\hline Europe & IS, TIA, ICH & FPG, OGTT, HbAlc & 700 & $147(2 \mid)$ & $365(52)$ & $188(27)$ \\
\hline Total & & & 3,165 & I,099 (35) & $\mathrm{I}, \mathrm{I} 85$ (37) & $88 I(28)$ \\
\hline
\end{tabular}

Note: Reproduced from Fonville S, Zandbergen AA, Koudstaal PJ, den Hertog HM. Prediabetes in patients with stroke or transient ischemic attack: prevalence, risk and clinical management. Cerebrovasc Dis. 20I4;37(6):393-400. Copyright (C) 2014 Karger Publishers, Basel, Switzerland. ${ }^{6}$

Abbreviations: DM, diabetes mellitus; TIA, transient ischemic attack; ICH, intracerebral hemorrhage; IS, ischemic stroke; OGTT, oral glucose tolerance test; FPG, fasting plasma glucose; HbAlc, glycosylated hemoglobin. 
Table 2 Overview of data assessing the prevalence of prediabetes and DM type 2 in stroke/TIA/ICH patients during the postacute/chronic stroke phase ( $\geq 3$ months after vascular event)

\begin{tabular}{|c|c|c|c|c|c|c|}
\hline Population & $\begin{array}{l}\text { Vascular } \\
\text { event }\end{array}$ & $\begin{array}{l}\text { Glucose } \\
\text { measurement }\end{array}$ & $\begin{array}{l}\text { Number } \\
\text { of patients }\end{array}$ & $\begin{array}{l}\text { Normoglycemic, } \\
\text { n (\%) }\end{array}$ & $\begin{array}{l}\text { Prediabetes, } \\
\text { n (\%) }\end{array}$ & $\begin{array}{l}\text { DM type 2, } \\
\text { n (\%) }\end{array}$ \\
\hline China & IS & OGTT & 111 & $64(58)$ & $26(23)$ & $21(19)$ \\
\hline Europe & $\mathrm{IS}, \mathrm{ICH}$ & OGTT & 62 & $26(42)$ & $23(37)$ & $13(2 \mid)$ \\
\hline US & IS, TIA & FPG, OGTT & 98 & $44(45)$ & $30(3 I)$ & $24(24)$ \\
\hline Europe & IS & OGTT & 96 & $34(35)$ & $26(27)$ & $36(38)$ \\
\hline US & IS & FPG, OGTT & 80 & $30(38)$ & $37(46)$ & $13(16)$ \\
\hline South Africa & IS & FPG, OGTT & 44 & $26(59)$ & $12(27)$ & $6(14)$ \\
\hline China & IS & FPG, OGTT & 107 & $42(39)$ & $37(35)$ & $28(26)$ \\
\hline Total & & & 598 & $266(44)$ & 191 (32) & |4| (24) \\
\hline
\end{tabular}

Note: Reproduced from Fonville S, Zandbergen AA, Koudstaal PJ, den Hertog HM. Prediabetes in patients with stroke or transient ischemic attack: prevalence, risk and clinical management. Cerebrovasc Dis. 2014;37(6):393-400. Copyright (C) 2014 Karger Publishers, Basel, Switzerland. ${ }^{6}$

Abbreviations: DM, diabetes mellitus; TIA, transient ischemic attack; ICH, intracerebral hemorrhage; IS, ischemic stroke; OGTT, oral glucose tolerance test; FPG, fasting plasma glucose.

genome-wide association studies found over 70 susceptibility loci responsible for DM type $2 .{ }^{25}$ Recently, Ng et al presented a meta-analysis of genome-wide association studies and provided insights into the genetic basis of DM type 2 . They also found 2 novel susceptibility loci for type 2 diabetes in African Americans. ${ }^{24} \mathrm{~A}$ well-known indicator of health as well as risk factor for developing serious health condition is waist-to-hip ratio (WHR). A smaller WHR indicates greater accumulation of gluteal fat and is associated with lower risk for DM type 2 development, ie, a higher WHR indicates more intra-abdominal fat accumulation and is associated with higher risk for type $2 \mathrm{DM}$. Recent studies identified loci for WHR after adjusting for body mass index (BMI). Therefore, these loci are indirectly associated with metabolic traits, ie, DM. ${ }^{26}$ More genome-wide association studies are needed especially among different ethnic groups for definite mapping of genetic loci associated with prediabetes and DM.

\section{Gestational diabetes}

In gestational diabetes, glucose tolerance returns to normal after birth. However, the woman is at risk of developing prediabetes or even DM. ${ }^{18,23}$

\section{Age}

The prevalence of DM and prediabetes is increasing with age. In the last few decades, the age of DM onset is decreasing. ${ }^{18}$

Table 3 Prediabetes risk factors

\begin{tabular}{ll}
\hline Non-modifiable risk factors & Modifiable risk factors \\
\hline Genetic factors & Obesity \\
Gestational diabetes & Physical activities \\
Age & Nutrition \\
& Others (low birth weight, \\
& exposure to intrauterine diabetic \\
& environment, and some of the \\
& inflammatory components) \\
\hline
\end{tabular}

\section{Obesity}

Obesity contributes to more than 300,000 deaths per year and nearly doubles the risk of death from all causes. ${ }^{27}$ Obesity is also the most important prediabetes and DM risk factor. Recent studies showed that obesity is a strong predictor for DM type 2 development. Also, obesity reduction may actually reduce the incidence of DM type 2. Different studies also demonstrated that waist circumference or WHR, which represents abdominal (visceral) fat condition, is actually a better indicator than BMI as the prediabetes risk factor. Data from these studies confirm that distribution of fat is more important than the total amount of fat. ${ }^{18}$ Moreover, loss of weight is associated with reduction in obesity-related cardiovascular disease risk, and increasing physical and sport activities are often associated with a decrease in waist circumference and cardio-metabolic risk, despite little change in BMI values. Thus, many authors suggest that BMI is probably a poor predictor of health status. ${ }^{18}$

\section{Physical activity}

Reduced physical activity in various populations has been a great contributor to increased obesity worldwide. Various prospective studies have shown that reduced physical activity is also an independent risk factor and predictor for the development of DM type $2 .{ }^{18}$

\section{Nutrition}

Low fiber diet, high total caloric intake, and high glycemic load are risk factors for both DM and prediabetes. Also, low polyunsaturated fatty acid/saturated fats ratio is well known predictor for the development of DM. ${ }^{18}$

It is well known that DM is a stroke risk factor. Also, DM is associated with an unfavorable functional outcome and slightly increased case fatality after stroke. ${ }^{6,28}$ Stress hyperglycemia in patients with and without DM is associated with increased mortality and poor functional outcome 
(modified Rankin Scale over 2) at 3 months after stroke. ${ }^{29}$ Also, both hyperglycemia and DM presence affect the functional outcome after treatment with intravenous tissuetype plasminogen activator. ${ }^{30,31}$ The Echoplanar Imaging Thrombolytic Evaluation Trial (EPITHET) studied the prognostic impact of DM and admission blood glucose on stroke outcome. EPITHET was a Phase II prospective, randomized, placebo-controlled, double-blinded, multinational study of acute ischemic stroke patients randomized to treatment with intravenous tPA or placebo 3-6 hours after onset and imaged with serial echo-planar magnetic resonance imaging. A preexisting diagnosis of DM was noted and baseline serum glucose level was measured. Intravenous tPA attenuated infarct growth in nondiabetic patients, but not in diabetic patients. In the tPA treatment hand, admission blood glucose was higher among patients with poor functional outcome. ${ }^{31}$

A recent study by Tanaka et al explored the association between diabetes, prediabetes, and short-term prognosis in acute ischemic stroke patients. They showed that both diabetes and prediabetes were associated with a poor early prognosis 30 days after acute ischemic stroke. ${ }^{32}$

Study by Fonville et al showed that half of the patients with IGT after vascular event (TIA or acute ischemic stroke) have persistent IGT. They presented a prediction model to recognize patients at risk of persistent IGT, with statin use, triglyceride, and fasting plasma glucose as the most significant predictors, which can be used to optimize secondary prevention. ${ }^{33}$

Although more studies are needed, it is most likely that prediabetic patients have intermediate risk of poor functional outcome, probably somewhere between the risk of people with normal metabolism of glucose and of DM patients. ${ }^{6}$

Prediabetes is also considered a recurrent stroke risk factor. ${ }^{6}$ There is a strong relation between fasting plasma glucose and 2-hour post load glucose levels on one side and risk of cardio and cerebrovascular events on the other. Study of Qiao et al indicates that 2-hour postload glucose level is a stronger predictor of stroke and future cardiovascular disease events than fasting plasma glucose levels. ${ }^{34}$ In a recent meta-analysis conducted by Ford et al, IFG and IGT were associated with modest increases in the cardiovascular disease risk. ${ }^{7}$ Similar results were obtained in a meta-analysis by Lee et al. They stated that prediabetes may be associated with a higher future risk of stroke, but the relative risk is modest and may reflect underlying confounding. ${ }^{35}$ Prediabetes has been observed to be associated with higher risk of cardiovascular events in younger adults. ${ }^{7}$ In 2013, Deedwania et al found no evidence that prediabetes is an independent risk factor for cardiovascular events or mortality in older patients; however, more studies of this type are required..$^{36}$

\section{Pathophysiology of hyperglycemia in acute ischemic stroke}

High blood glucose levels are often present in patients with acute stroke. Interestingly, almost half of these patients have no history of DM. ${ }^{37}$ These high levels of blood glucose are either transient or persistent, reflecting previously undiagnosed prediabetes or even DM. ${ }^{6}$ On the other hand, serious stress, like stroke, can be a trigger for acute stress reaction that stimulates the hypothalamus-pituitary-adrenal axis, which consequently leads to a significant release of catecholamines, glucagon, and cortisol. ${ }^{6}$ This can lead to states of insulin resistance, gluconeogenesis, and glycogenolysis presented by hyperglycemia. ${ }^{38,39}$ Beside this theory, there are evidences that state of hyperglycemia after stroke is due to activation of an inflammatory reaction. ${ }^{6,39,40}$

\section{Pathophysiology of prediabetes}

IGT and IFG are intermediate metabolic states in glucose metabolism that exist between normal glucose tolerance and DM. However, they do not share the same pathophysiological mechanisms. In people with normal glucose metabolism, ingested glucose uptake occurs in tissues that are insulin insensitive (such as brain and red blood cells). The liver is the place of the endogenous glucose production. Glucose uptake and glucose production are 2 complementary processes: after ingestion of glucose, insulin secretion is activated by the increased plasma glucose levels. This reaction is followed by suppression of glucose production, and glucose uptake, primarily by muscles, is stimulated to remain in the normoglycemic state. Both impaired beta-cell function and insulin resistance, the primary defects observed in DM type 2, are detected in patients with IFG and IGT. Different epidemiological statistics between IFG and IGT shows that there are different pathophysiological mechanisms of both the conditions, and recent clinical studies suggest that the site of insulin resistance varies between these 2 disorders. While IGT patients have severe muscle insulin resistance with only mild hepatic insulin resistance, subjects with IFG have marked hepatic insulin resistance with normal or almost normal insulin sensitivity of muscles. Both IGT and IFG are characterized by a reduction in early-phase insulin secretion, while patients with IGT also have impaired late-phase insulin secretion. These differences may require different therapeutic strategies to prevent progression to DM type 2.,22 Patients with concomitant IGT and IFG have both muscle and hepatic resistance of insulin and decreased both phases of 
insulin responses to oral glucose uptake, which might explain the higher risk in these patients to develop DM compared with patients with only IGT or IFG alone. ${ }^{6,41}$ These data gain importance when prevalence of IGT and IFG is taken into account. The prevalence of both IGT and IFG varies significantly depending on ethnicity, ranging from a low of $6.3 \%$ in Chinese people to a high of $20.3 \%$ in the Swedish population. ${ }^{22,42,43}$ In European population, the prevalence of isolated IGT and IFG is $8.8 \%$ and $6.9 \%$, respectively. Percentage of IGT patients with IFG is $26 \%$, and percentage of IFG patients with IGT is $31 \% .^{22,44}$

Harada et al confirmed that insulin sensitivity can be impaired in patients who suffered from ischemic stroke, probably due to decreased hepatic expression of insulin receptors and upregulation of gluconeogenesis, which can lead to $\mathrm{IGT}^{40}$

Clear understanding of the pathophysiological mechanisms that characterize IFG and IGT provides insights about therapy to stop or slow progression to DM type 2. IFG patients, who predominantly have hepatic insulin resistance, are most likely to benefit from drugs that reduce liver insulin resistance such as metformin, while patients with IGT, who suffer from impaired insulin secretion and muscle insulin resistance, are more likely to gain benefit from drugs that improve skeletal muscle insulin resistance, such as peroxisome proliferator-activated receptor- $\gamma$ agonists, in combination with agents that improve insulin secretion, such as analog of glucagon like peptide-1..$^{22,45,46}$

\section{Prevention of prediabetes and DM}

There is an urgent need for prevention to reduce the number of patients with prediabetes and DM type 2, ie, cardiovascular and cerebrovascular diseases associated with these conditions. Prediabetes is a good warning sign. Herman et al even suggested simple chair-side screening for prediabetes and DM in dental offices, because most Americans see dentists at least once a year. ${ }^{47}$ Recent studies showed that early recognition and intervention to improve glucose control will prevent the progression of prediabetes to DM type 2 and also will result in reduced incidence, comorbidity, and complication of DM. ${ }^{23}$

Hopper et al conducted a meta-analysis of prospective, randomized controlled trials from literature to investigate if treatment of IGT and IFG may prevent or delay the onset of DM and thus potentially reduce cardiovascular events. They concluded that despite interventions being successful in slowing progression to DM, this did not result in reductions in all-cause or cardiovascular mortality, or myocardial infarction, with the exception of stroke. ${ }^{48}$

The core of prevention and treatment should be lifestyle modifications, should be provided to all patients, and should be reinforced in every visit of the patient. This approach can delay or even prevent the progression from prediabetes to DM, and also can reduce both microvascular and macrovascular disease risks and complications. Lifestyle modifications also improve risk factors for DM (and prediabetes), hypertension, dyslipidemia, hyperglycemia, and obesity. People with prediabetes should reduce body weight by $5 \%$ in 6 months and should remain at this level for a long time. ${ }^{18} \mathrm{~A}$ long-term follow-up study showed that lifestyle modification resulted in DM incidence reduction, which also continued after the individual lifestyle counseling was stopped. ${ }^{18,49}$ Weight loss also reduces fat mass, BMI, high blood pressure, blood glucose levels, triglycerides, and low density lipoprotein (LDL) cholesterol levels. ${ }^{18}$

Diet interventions include increased fiber intake, carbohydrate intake limitations, and, of course, calorie restriction. For patients with high blood pressure, dietary recommendations also include lower sodium intake and limitation in alcohol consumption. ${ }^{18}$ Physical activity of moderate intensity for 0.5-1 hour daily, at least 4 days weekly (150 minutes per week), is highly recommended. ${ }^{23}$ Da Qing Study ${ }^{23}$ conducted in Chinese patients with a mean age of 45 years and prediabetes examined the effect of diet and exercise on DM prevention in these subjects. ${ }^{18,23}$ The diet intervention (6-year diet) reduced the risk of DM type 2 development by $31 \%$. On the other hand, physical activity alone reduced the risk by $45 \%$. A combination of these lifestyle modifications (both diet and exercise) reduced the risk of developing DM type 2 by $42 \% .^{18,23}$ Similar results were obtained in Finnish Diabetes Prevention Study. Lifestyle modification was followed for 3.2 years, and it was conducted among 522 obese patients with IGT and a control group without lifestyle modifications. Lifestyle intervention was based on achieving and maintaining ideal body weight, increasing fiber intake, reducing fat intake, and also increasing physical activity. After 2 years, the DM incidence was reduced as much as 50\% in the modification group compared to the control group. ${ }^{18}$ Although lifestyle changes are the basis of prevention, it is very difficult to follow them in real practice, especially without help from an educated health care practitioner. Successful intervention is $5 \%$ body weight reduction in 6 months or reduced body weight of $2 \mathrm{~kg}$ per month. On the other hand, not all of the patients can accept and maintain lifestyle modifications, 
especially those at high risk; so, frequently another intervention is needed, ie, with drugs/medication. ${ }^{18}$

One of the largest randomized trials called Diabetes Prevention Program (DPP), which was conducted among 3,234 patients with prediabetes in America, compared lifestyle modification and medication intervention with metformin with a control group over 2.8 years. ${ }^{18,23}$ DPP study reported that both metformin and lifestyle modification have positive effects on DM prevention and returning prediabetes to a normal condition. Also, lifestyle change was more effective than metformin, and there was a lower mortality rate in the lifestyle intervention group. The cost-effectiveness between these 2 groups was comparable. ${ }^{18,23}$ A similar study was done in Asian-Indian population in Indian Diabetes Prevention Program, which was a prospective study that evaluated whether lifestyle modification and medication (also metformin) could influence progression of IGT to DM. ${ }^{18,23}$ In this population, progression of IGT to DM was extremely high. Both metformin and lifestyle modification reduced the progression of IGT to DM. On the other hand, there was no added benefit from combining them compared to single treatment alone. The risk of developing DM was reduced by $28.5 \%$ in the lifestyle modification group, $26.4 \%$ the in metformin arm, and $28.2 \%$ in the combination group.

Drug intervention for prevention of DM is usually recommended as secondary intervention, especially if lifestyle intervention does not lead to successful weight loss. In such cases, the use of drug/medication should be started. ${ }^{18,50}$

\section{Metformin}

DPP study showed that metformin in the dose of $850 \mathrm{mg}$ 2 times a day reduced DM development by $31 \%$ in 2.8 years compared to placebo. The risk reduction was higher in the group with BMI over $30 \mathrm{~kg} / \mathrm{m}^{2}$, with relative risk reduction reaching $35 \%$, while in patients with BMI of $22-30 \mathrm{~kg} / \mathrm{m}^{2}$, the relative risk reduction was only $3 \%$. On the other hand, different results were found in Indian Diabetes Prevention Program, which showed a benefit from metformin consumption in those with BMI less than $30 \mathrm{~kg} / \mathrm{m}^{2}$, considering that in Asian people obesity presents at a lower BMI (ie, over $25 \mathrm{~kg} / \mathrm{m}^{2}$ ). ${ }^{18}$

\section{Glitazones}

In the DPP study, troglitazone treatment was withdrawn due to hepatotoxicity. In the Troglitazone In Prevention Of Diabetes (TRIPOD) study, treatment with troglitazone has caused cumulative reduction of DM incidence to 0 point in
3 years. Results of a DREAM cohort study using ramipril and rosiglitazone with a large multiethnic population showed that patients with prediabetes who had received rosiglitazone showed a decrease of $60 \%$ in progression to DM compared to $25 \%$ in placebo group. ${ }^{18,23,51}$ Also, $70 \%$ of them returned to normal glucose tolerance. However, patients receiving rosiglitazone showed increased incidence of congestive heart failure and high incidence of body weight increase..$^{18,51}$

\section{Orlistat}

Orlistat acts by a mechanism of inhibiting an enzyme that breaks down triglycerides in the intestine. Orlistat may cause significant weight loss of 3-5 kg over 6 months, which could be maintained for 4 years. Treatment of obese prediabetes patients with this drug, as an adjuvant treatment, can reduce the risk of DM type $2 .{ }^{18}$ However, orlistat caused gastrointestinal side effects in many patients, which is the main reason why they stopped using this drug. ${ }^{23}$

\section{Acarbose}

Acarbose is an active inhibitor of an enzyme that digests carbohydrates. In the STOP-NIDDM study (Study to Prevent Non-Insulin-Dependent Diabetes Mellitus), acarbose reduced the DM risk by $25 \%$ and the risk for cardiovascular disease by almost $50 \% .{ }^{18}$ However, the gastrointestinal side effects caused a $31 \%$ dropout rate in the study group and only $19 \%$ in the placebo group. Therefore, these facts limited its use for prevention of DM. Authors recommend acarbose use for DM prevention and cardiovascular risk reduction in those patients who can tolerate the side effects. ${ }^{52}$ Also, acarbose may reduce body weight and lipid levels, as well as the incidence of newly diagnosed hypertension by $34 \%$, which was confirmed in the STOP-NIDDM study. Another positive effect is reduction of LDL proatherosclerotic activity in prediabetes patients. ${ }^{18}$

\section{Conclusion}

In conclusion, the most effective prediabetes and DM prevention is based on healthy way of life. Everyone is encouraged to perform moderate physical activity, at least 4 times a week. Also, one should always maintain a normal healthy weight, and adults with BMI over $23 \mathrm{~kg} / \mathrm{m}^{2}$ should be encouraged to achieve and maintain a healthy weight Children should be encouraged to achieve and maintain the normal range weight for their height. Also, each patient with acute stroke or TIA needs to be subjected to screening for glucose metabolism disorder. Guided by personal experience 
and expert opinions and guidelines, we think that the best approach is personalized medical approach with the emphasis on prevention.

\section{Disclosure}

The authors report no conflicts of interest in this work.

\section{References}

1. Feigin VL, Forouzanfar MH, Krishnamurthi R, et al; Global Burden of Diseases, Injuries, and Risk Factors Study 2010 (GBD 2010) and the GBD Stroke Experts Group. Global and regional burden of stroke during 1990-2010: findings from the Global Burden of Disease Study 2010. Lancet. 2014;383(9913):245-254.

2. Buysschaert M, Bergman M. Definition of prediabetes. Med Clin North Am. 2011;95(2):289-297.

3. Roquer J, Rodríguez-Campello A, Cuadrado-Godia E, et al. Ischemic stroke in prediabetic patients. J Neurol. 2014;261(10):1866-1870.

4. American Diabetes Association. Position statement: diagnosis and classification of diabetes mellitus. Diabetes Care. 2010;33 (Suppl 1): S62-S69.

5. Colagiuri S. Epidemiology of prediabetes. Med Clin North Am. 2011; 95(2):299-307.

6. Fonville S, Zandbergen AA, Koudstaal PJ, den Hertog HM. Prediabetes in patients with stroke or transient ischemic attack: prevalence, risk and clinical management. Cerebrovasc Dis. 2014;37(6):393-400.

7. Ford ES, Zhao G, Li C. Pre-diabetes and the risk for cardiovascular disease: a systematic review of the evidence. J Am Coll Cardiol. 2010; 55(13): 1310-1317.

8. Vermeer SE, Sandee W, Algra A, Koudstaal PJ, Kappelle LJ, Dippel DW; Dutch TIA Trial Study Group. Impaired glucose tolerance increases stroke risk in nondiabetic patients with transient ischemic attack or minor ischemic stroke. Stroke. 2006;37(6):1413-1417.

9. Tabák AG, Herder C, Rathmann W, Brunner EJ, Kivimäki M. Prediabetes: a high-risk state for diabetes development. Lancet. 2012; 379(9833):2279-2290.

10. American Diabetes Association. Standards of medical care in diabetes2012. Diabetes Care. 2012;35(Suppl 1):S11-S63.

11. Chen CM, Yeh MC. The prevalence and determinants of impaired fasting glucose in the population of Taiwan. BMC Public Health. 2013;13:1123.

12. Longmore M, Wilkinson I, Turmezei T, Cheung CK. Oxford Handbook of Clinical Medicine. 7th ed. Oxford: Oxford University Press; 2007.

13. World Health Organization. Definition, diagnosis and classification of diabetes mellitus and its complications: report of a WHO consultation. Geneva: World Health Organization; 1999.

14. American Diabetes Association. Diagnosis and classification of diabetes mellitus. Diabetes Care. 2013;36(Suppl 1):S67-S74.

15. Ackermann RT, Cheng YJ, Williamson DF, Gregg EW. Identifying adults at high risk for diabetes and cardiovascular disease using hemoglobin A1c National Health and Nutrition Examination Survey 2005-2006. Am J Prev Med. 2011;40(1):11-17.

16. Kumar S, Singh R, Vasudeva N, Sharma S. Acute and chronic animal models for the evaluation of anti-diabetic agents. Cardiovasc Diabetol. 2012;11:9.

17. Bansal N. Prediabetes diagnosis and treatment: A review. World $J$ Diabetes. 2015;6(2):296-303.

18. Indonesian Diabetes Association. Guidelines on the management and prevention of prediabetes. Acta Med Indones. 2014;46(4): 348-359.

19. Kernan WN, Viscoli CM, Inzucchi SE, et al. Prevalence of abnormal glucose tolerance following a transient ischemic attack or ischemic stroke. Arch Intern Med. 2005;165(2):227-233.
20. Matz K, Keresztes K, Tatschl C, et al. Disorders of glucose metabolism in acute stroke patients: an underrecognized problem. Diabetes Care. 2006;29(4):792-797.

21. Urabe T, Watada H, Okuma Y, et al. Prevalence of abnormal glucose metabolism and insulin resistance among subtypes of ischemic stroke in Japanese patients. Stroke. 2009;40(4):1289-1295.

22. Abdul-Ghani MA, Tripathy D, DeFronzo RA. Contributions of betacell dysfunction and insulin resistance to the pathogenesis of impaired glucose tolerance and impaired fasting glucose. Diabetes Care. 2006; 29(5):1130-1139.

23. Alberti KG, Zimmet P, Shaw J. International Diabetes Federation: a consensus on type 2 diabetes prevention. Diabet Med. 2007;24(5): $451-463$.

24. Ng MC, Shriner D, Chen BH, et al; MEta-analysis of type 2 DIabetes in African Americans Consortium. Meta-analysis of genome-wide association studies in African Americans provides insights into the genetic architecture of type 2 diabetes. PLoS Genet. 2014;10(8): e1004517.

25. McCarthy MI. Genomics, type 2 diabetes, and obesity. N Engl J Med. 2010;363(24):2339-2350.

26. Shungin D, Winkler TW, Croteau-Chonka DC, et al. New genetic loci link adipose and insulin biology to body fat distribution. Nature. 2015; 518(7538):187-196.

27. Air EL, Kissela BM. Diabetes, the metabolic syndrome, and ischemic stroke: epidemiology and possible mechanisms. Diabetes Care. 2007; 30(12):3131-3140.

28. Luitse MJ, Biessels GJ, Rutten GE, Kappelle LJ. Diabetes, hyperglycaemia, and acute ischaemic stroke. Lancet Neurol. 2012;11(3): 261-271.

29. Van Swieten JC, Koudstaal PJ, Visser MC, Schouten HJ, van Gijn J. Inter observer agreement for the assessment of handicap in stroke patients. Stroke. 1988;19(5):604-607.

30. Poppe AY, Majumdar SR, Jeerakathil T, Ghali W, Buchan AM, Hill MD; Canadian Alteplase for Stroke Effectiveness Study Investigators. Admission hyperglycemia predicts a worse outcome in stroke patients treated with intravenous thrombolysis. Diabetes Care. 2009; 32(4):617-622.

31. De Silva DA, Ebinger M, Christensen S, et al; Echoplanar Imaging Thrombolytic Evaluation Trial (EPITHET) Investigators. Baseline diabetic status and admission blood glucose were poor prognostic factors in the EPITHET trial. Cerebrovasc Dis. 2010;29(1):14-21.

32. Tanaka R, Ueno Y, Miyamoto N, et al. Impact of diabetes and prediabetes on the short-term prognosis in patients with acute ischemic stroke. J Neurol Sci. 2013;332(1-2):45-50.

33. Fonville S, den Hertog HM, Zandbergen AA, Koudstaal PJ, Lingsma HF. Occurrence and predictors of persistent impaired glucose tolerance after acute ischemic stroke or transient ischemic attack. J Stroke Cerebrovasc Dis. 2014;23(6):1669-1675.

34. Qiao Q, Pyörälä K, Pyörälä M, et al. Two hour glucose is a better risk predictor for incident coronary heart disease and cardiovascular mortality than fasting glucose. Eur Heart J. 2002;23(16):1267-1275.

35. Lee M, Saver JL, Hong KS, Song S, Chang KH, Ovbiagele B. Effect of pre-diabetes on future risk of stroke: meta-analysis. BMJ. 2012; 344:e3564.

36. Deedwania P, Patel K, Fonarow GC, et al. Prediabetes is not an independent risk factor for incident heart failure, other cardiovascular events or mortality in older adults: findings from a population-based cohort study. Int J Cardiol. 2013;168(4):3616-3622.

37. Capes SE, Hunt D, Malmberg K, Pathak P, Gerstein HC. Stress hyperglycemia and prognosis of stroke in nondiabetic and diabetic patients: a systematic overview. Stroke. 2001;32(10):2426-2432.

38. Dungan KM, Braithwaite SS, Preiser JC. Stress hyperglycaemia. Lancet. 2009;373(9677):1798-1807.

39. Kruyt ND, Biessels GJ, Devries JH, Roos YB. Hyperglycemia in acute ischemic stroke: pathophysiology and clinical management. Nat Rev Neurol. 2010;6(3):145-155. 
40. Harada S, Fujita-Hamabe W, Tokuyama S. Ischemic stroke and glucose intolerance: a review of the evidence and exploration of novel therapeutic targets. J Pharmacol Sci. 2012;118(1):1-13.

41. Nathan DM, Davidson MB, DeFronzo RA, et al; American Diabetes Association. Impaired fasting glucose and impaired glucose tolerance: implications for care. Diabetes Care. 2007;30(3):753-759.

42. Ko GT, Chan JC, Woo J, Cockram CS. Use of the 1997 American Diabetes Association diagnostic criteria for diabetes in a Hong Kong Chinese population. Diabetes Care. 1998;21(12):2094-2097.

43. Larsson H, Berglund G, Lindgärde F, Ahrén B. Comparison of ADA and WHO criteria for diagnosis of diabetes and glucose intolerance. Diabetologia. 1998;41(9):1124-1125.

44. de Vegt F, Dekker JM, Stehouwer CD, Nijpels G, Bouter LM, Heine RJ. The 1997 American Diabetes Association criteria versus the 1985 World Health Organization criteria for the diagnosis of abnormal glucose tolerance: poor agreement in the Hoorn Study. Diabetes Care. 1998; 21(10):1686-1690.

45. Knowler WC, Barrett-Connor E, Fowler SE, et al; Diabetes Prevention Program Research Group. Reduction in the incidence of type 2 diabetes with lifestyle intervention or metformin. N Engl J Med. 2002; 346(6):393-403.

46. Buchanan TA, Xiang AH, Peters RK, et al. Preservation of pancreatic beta-cell function and prevention of type 2 diabetes by pharmacological treatment of insulin resistance in high-risk Hispanic women. Diabetes. 2002;51(9):2796-2803.
47. Herman WH, Taylor GW, Jacobson JJ, Burke R, Brown MB. Screening for prediabetes and type 2 diabetes in dental offices. J Public Health Dent. 2015;75(3):175-182.

48. Hopper I, Billah B, Skiba M, Krum H. Prevention of diabetes and reduction in major cardiovascular events in studies of subjects with prediabetes: meta-analysis of randomised controlled clinical trials. Eur J Cardiovasc Prev Rehabil. 2011;18(6):813-823.

49. American Diabetes Association. Standards of medical care in diabetes2009. Diabetes Care. 2009;32(Supp1 1):S13-S61.

50. Gillies CL, Abrams KR, Lambert PC, et al. Pharmacological and lifestyles interventions to prevent or delay type 2 diabetes in people with impaired glucose tolerance: systematic review and meta analysis. BMJ. 2007; 334(7588):299.

51. American Diabetes Association. Standards of medical care in diabetes2014. Diabetes Care. 2014;37(Supp1 1):S14-S80.

52. Hanefeld M. Cardiovascular benefits and safety profile of acarbose therapy in prediabetes and established type 2 diabetes. Cardiovasc Diabetol. 2007;6:20.
Neuropsychiatric Disease and Treatment

\section{Publish your work in this journal}

Neuropsychiatric Disease and Treatment is an international, peerreviewed journal of clinical therapeutics and pharmacology focusing on concise rapid reporting of clinical or pre-clinical studies on a range of neuropsychiatric and neurological disorders. This journal is indexed on PubMed Central, the 'PsycINFO' database and CAS,

\section{Dovepress}

and is the official journal of The International Neuropsychiatric Association (INA). The manuscript management system is completely online and includes a very quick and fair peer-review system, which is all easy to use. Visit http://www.dovepress.com/testimonials.php to read real quotes from published authors. 